\title{
ESTUDO DA ADSORÇÃO SOBRE CHAR OBTIDO PELA PIRÓLISE LENTA DE CAPIM ELEFANTE
}

\author{
M. B. $\operatorname{SONDA}^{1}$ e D. TOSS $^{1}$ \\ ${ }^{1}$ Universidade de Caxias do Sul, Centro de Ciências Exatas e Tecnologia. \\ E-mail para contato: dtoss@ucs.br
}

\begin{abstract}
RESUMO - O desenvolvimento de fontes renováveis, em substituição aos recursos fósseis, vem crescendo a cada dia. O capim elefante, com elevado crescimento e produção de biomassa vegetal, apresenta alto potencial como fonte de energia. Dentre os processos de transformação da biomassa, destaca-se a pirólise lenta, que favorece a formação de carvão vegetal (char). A pirólise lenta foi realizada em três diferentes taxas de aquecimento: 5, 10 e $15^{\circ} \mathrm{C} / \mathrm{min}$. O char obtido foi analisado pela microscopia eletrônica de varredura e as isotermas de adsorção foram obtidas com o uso de ácido acético. $\mathrm{Na}$ taxa de $5{ }^{\circ} \mathrm{C} / \mathrm{min}$ observa-se um char com tamanho de poros menores e em quantidade mais elevada. Nesta mesma taxa, a isoterma de adsorção segue o modelo de monocamadas. Nas demais taxas o que se observa são poros maiores e desuniformes, o que resultou em isotermas em multicamadas. Assim, o carvão obtido em $5{ }^{\circ} \mathrm{C} /$ min pode ser aplicado em processos de separação por adsorção, porém uma ativação se faz necessária.
\end{abstract}

\section{INTRODUÇÃO}

A produção de energia tem sido a força motriz para o crescimento da economia global, tendo em vista que a mesma é considerada um dos elementos mais importantes para o desenvolvimento socioeconômico dos países. A geração de energia está na maioria das vezes relacionada com fontes de energia não renováveis, como petróleo e carvão. Atualmente, a busca em se obter uma forma de energia limpa e renovável, visando reduzir a dependência de combustíveis fósseis, vem crescendo a cada dia (Soyhan, 2009). O capim elefante (Pennisetum purpureum), por ser uma espécie de rápido crescimento e de elevada produção de biomassa vegetal, apresenta um alto potencial para uso como fonte alternativa de energia. Além disso, deve-se destacar que o capim elefante é altamente eficiente na fixação de gás carbônico e pode ser convertido em bio-óleo, biogás e carvão através do processo termoquímico de pirólise (Strezov et al., 2008).

A pirólise é a decomposição térmica que ocorre em uma atmosfera inerte na ausência de oxigênio e é a primeira etapa dos processos de combustão e gaseificação. Essa reação de degradação de biomassa é descrita por mecanismos reacionais que controlam o processo, por isso 
é de extrema importância o controle desses mecanismos para a determinação dos parâmetros cinéticos envolvidos no processo. O termo pirólise A pirólise recebe diferentes denominações dependendo das condições operacionais utilizadas. Na pirólise lenta, ou carbonização, o emprego de baixas temperaturas e longos tempos de residência favorece a produção de carvão vegetal (char) (Bridgwater et al., 2003).

A adsorção é um fenômeno de superfície no qual um material (soluto) é removido de uma fase fluida (líquida ou gasosa) e acumulado na superfície de uma fase sólida. Geralmente, a adsorção ocorre como resultado de forças não balanceadas na superfície do sólido que atraem as moléculas de um fluido em contato por um tempo finito. Para as forças de atração serem balanceadas em todas as direções, o adsorvente (fase sólida) tende a adsorver moléculas presentes na fase fluida (Cavalcante, 1998).

Os dados de equilíbrio são obtidos através das isotermas de adsorção, que relacionam a quantidade de material adsorvido com a concentração de equilíbrio do soluto na solução (Sulaymon et al., 2009). O modo mais comum de obter uma isoterma de adsorção é determinar a concentração da solução antes e depois da adsorção, em várias concentrações iniciais de adsorvente, buscando encontrar a quantidade correta de adsorvente necessário para a remoção do material solúvel (Annadurai et al., 2008). As isotermas de adsorção podem ser classificadas em seis tipos característicos, conforme apresenta a Figura 1.
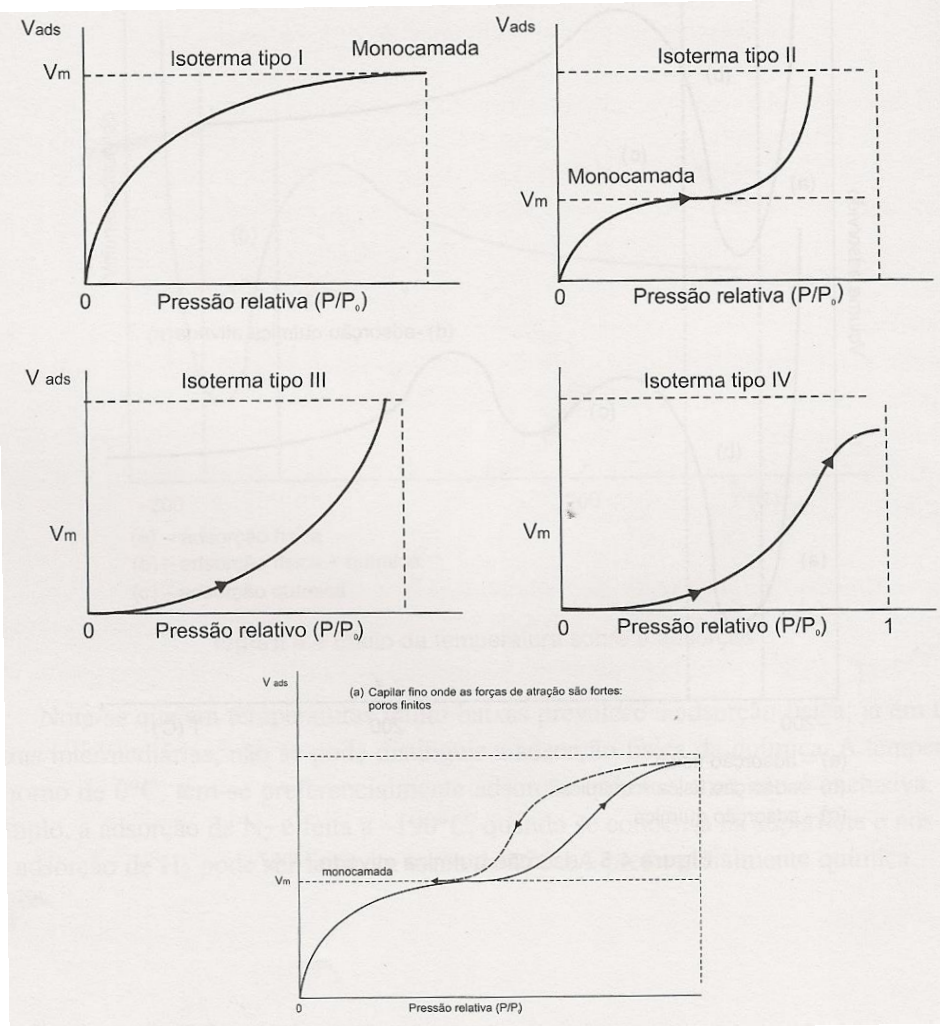

Figura 1 - Tipos de isotermas de adsorção. 


\section{9 a 22 de outubro de 2014 \\ Florianópolis/SC}

A isoterma representada pelo tipo I caracteriza-se por atingir a saturação a baixas temperaturas e pela formação de uma monocamada completa. Isotermas deste tipo também são características de sólidos microporosos. A isoterma do tipo II representa uma monocamada incompleta, seguida de uma condensação capilar e acontece principalmente em materiais macroporosos. Já na isoterma III, a quantidade adsorvida tende ao infinito, correspondendo à adsorção física em camadas múltiplas sobrepostas e ocorre em sólidos não porosos ou macroporosos. A isoterma do tipo IV assemelha-se à isoterma do tipo III, porém atinge saturação com o aumento de pressão, correspondendo à condensação completa nos capilares. A isoterma $\mathrm{V}$ atinge igualmente a saturação dos poros, porém apresenta histerese durante a dessorção: a curva descendente não é igual à de adsorção ascendente, justamente porque o gás condensado nos poros não evapora facilmente, recondensando devido à formação de menisco nos capilares. Esta curva representa os sólidos macro ou mesoporos e a quantidade adsorvida tende a um valor finito, a qual corresponde ao enchimento dos poros (Schmal, 2011).

\section{MATERIAS E MÉTODOS}

\subsection{Capim Elefante}

Foram utilizadas amostras de capim elefante pertencentes à espécie Pennisetum purpureum provenientes do Instituto de Biotecnologia da Universidade de Caxias do Sul. O corte do capim foi realizado no mês de dezembro de 2012, após crescimento de 4 meses. As amostras foram previamente secas em condições ambiente, trituradas em moinho de facas e peneiradas, selecionando-se uma amostra com diâmetro médio de $6,30 \mathrm{~mm}$.

\subsection{Condições Operacionais}

O estudo da pirólise lenta do capim elefante foi realizado em um reator de bancada da marca SANCHIS, que opera em batelada. Para cada ensaio alimentou-se o reator com $8 \mathrm{~g}$ de biomassa. $\mathrm{O}$ processo de pirólise foi realizado com uma vazão de gás nitrogênio de $80 \mathrm{~mL} / \mathrm{min}$ e temperatura de $500{ }^{\circ} \mathrm{C}$, parâmetros mantidos para as três diferentes corridas experimentais. A fim de avaliar o rendimento do processo de pirólise lenta, variou-se a taxa de aquecimento em 5, $10 \mathrm{e}$ $15^{\circ} \mathrm{C} /$ min. $\mathrm{O}$ tempo de residência das amostras no reator, depois de atingida a temperatura de $500{ }^{\circ} \mathrm{C}$, foi de $30 \mathrm{~min}$.

\subsection{Caracterização do Char}

A caracterização do char produzido no processo de pirólise lenta foi realizada por meio do ensaio de MEV, que permite observar a mudança nas propriedades de textura e morfologia das amostras após o processo de pirólise. As análises foram realizadas no Laboratório de 
Caracterização de Materiais da Universidade de Caxias do Sul, em um equipamento da marca Shimadzu modelo SSX-550.

\subsection{Isotermas de Adsorção}

Para a elaboração das isotermas de adsorção foi realizado o procedimento que estuda a adsorção do ácido acético sobre o char.

Procedimento experimental: Pesou-se 5 amostras de $0,2 \mathrm{~g}$ do char produzido em cada taxa de aquecimento do ensaio de pirólise e colocou-se cada uma em um Erlenmeyer, totalizando 15 amostras. Preparou-se 5 soluções com ácido acético $0,509 \mathrm{~mol} / \mathrm{L}$, em balões de $50 \mathrm{ml}$, nas seguintes concentrações: 0,509 mol/L, 0,2545 mol/L, 0,1221 mol/L, 0,061 mol/Le 0,0305 mol/L. Foram preparadas 3 soluções para cada concentração, totalizando 15 soluções. Após, colocou-se cada solução preparada no Erlenmeyer que continha $0,2 \mathrm{~g}$ do char produzido nas diferentes taxas de aquecimento e cobriu-se o mesmo. Transcorrida $1 \mathrm{~h}$, filtraram-se as amostras. Em seguida, ao material filtrado foram adicionadas algumas gotas de fenolftaleína e o mesmo foi titulado com hidróxido de sódio $0,458 \mathrm{~mol} / \mathrm{L}$. A partir da titulação inicial do ácido acético e dos resultados das titulações de cada amostra, foi possível fazer os cálculos necessários para a obtenção das isotermas de adsorção.

\section{RESULTADOS E DISCUSSÃO}

A Tabela 1 apresenta os resultados referentes aos rendimentos de char obtidos no ensaio de pirólise. O processo de pirólise lenta empregando baixas taxas de aquecimento favorece a formação de carvão. Quando se emprega taxas mais elevadas, prioriza-se a formação de compostos voláteis, o que é visto pelos resultados obtidos.

Tabela 1 - Rendimento em char obtidos na pirólise

\begin{tabular}{cc}
\hline Taxa de aquecimento $\left({ }^{\circ} \mathrm{C} / \mathrm{min}\right)$ & Rendimento $(\%)$ \\
\hline 5 & 25,0 \\
10 & 21,4 \\
15 & 19,0 \\
\hline
\end{tabular}

\subsection{Caracterização do Char (MEV)}

A Figura 2 apresenta o MEV do char produzido nas diferentes taxas de aquecimento empregadas. 

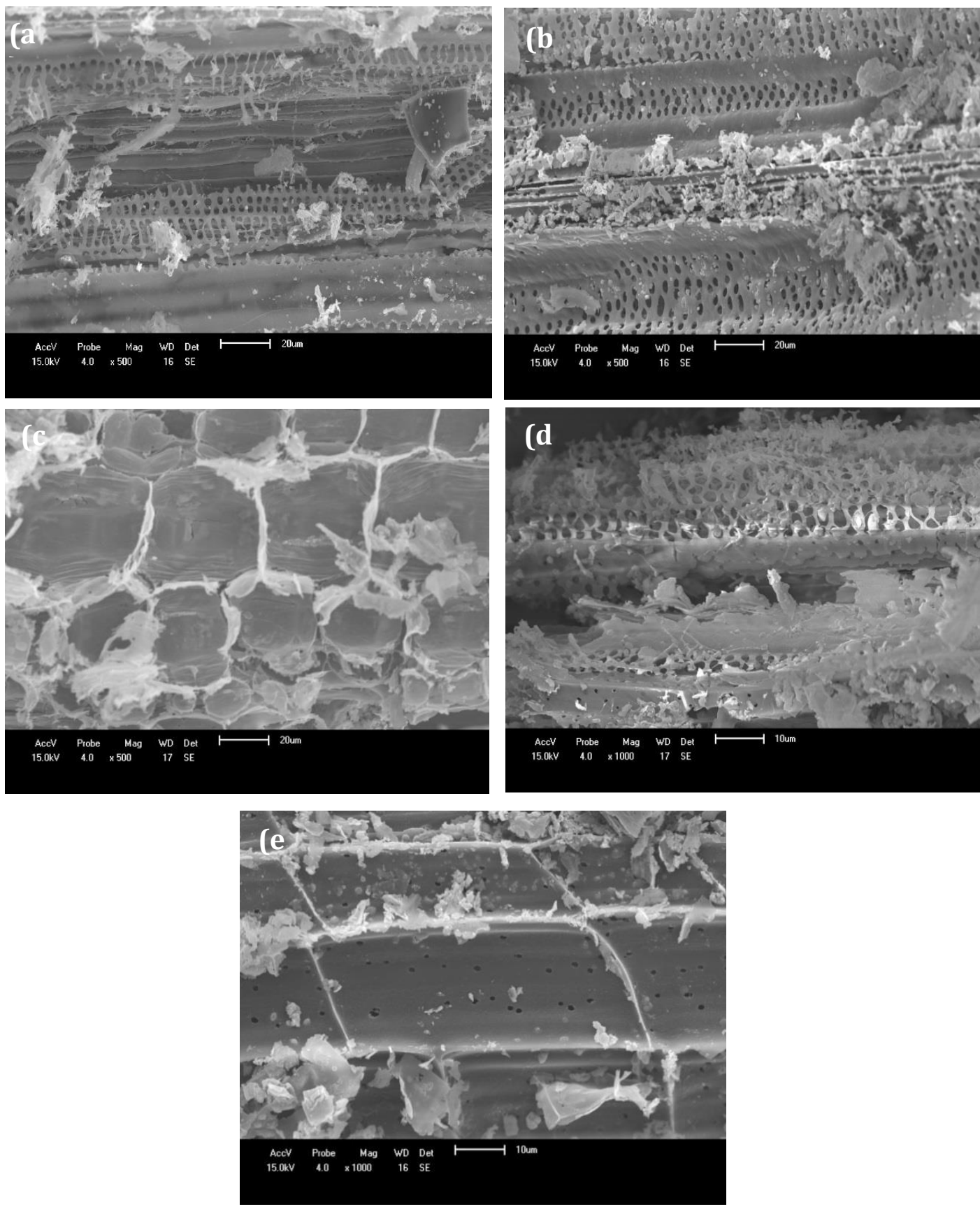

Figura 2 - MEV do char produzido.

Nota: (a), (b) e (c) taxa de aquecimento de 5,10 e $15^{\circ} \mathrm{C} / \mathrm{min}$, respectivamente, e aumento de 500x; (d) e (e) taxa de aquecimento de 5 e $10^{\circ} \mathrm{C} / \mathrm{min}$, respectivamente, e aumento de 1000x; 
Segundo Cetin et al. (2005) quando baixas taxas de aquecimento são empregadas, a porosidade natural do material permite a liberação da matéria volátil sem que ocorra grandes alterações morfológicas no material. No entanto, taxas de aquecimento mais elevadas, modificam praticamente toda a estrutura celular do material. Isso pode ser atribuído à fusão da estrutura celular e, assim, à ocorrência de transformações plásticas.

Observando a Figura 2 (a), (b) e (c), é possível avaliar que, quando menores taxas de aquecimento são empregadas no processo de pirólise, a remoção do material volátil aparece de forma mais clara, isso porque ocorre uma maior preservação da estrutura do material. Analisando o resultado do MEV para a taxa de aquecimento de $10{ }^{\circ} \mathrm{C} / \mathrm{min}$ - Figura 2 (b) - observa-se a presença de um número maior de cavidades do que na taxa de aquecimento de $5{ }^{\circ} \mathrm{C}$. $\mathrm{min}^{-1}$ - Figura 2 (a) -, o que caracteriza uma maior remoção da matéria volátil. Na taxa de aquecimento de $15^{\circ} \mathrm{C} / \mathrm{min}$ - Figura 2 (c) - não é possível visualizar a remoção dos voláteis devido à grande modificação na estrutura celular do material.

A Figura 2 (d) e (e) evidencia que o char é composto por poros de tamanhos variados e irregulares. Na taxa de $5{ }^{\circ} \mathrm{C} / \mathrm{min}$ - Figura 2 (d) - observa-se um char com tamanho de poros menores. Segundo Sharma et al. (2001) os poros presentes no material são, possivelmente, originados a partir da intensa eliminação de compostos voláteis durante as reações secundárias de pirólise.

\subsection{Isotermas de Adsorção}

Em posse dos resultados da adsorção de ácido acético, pode-se observar dois tipos distintos de isotermas (Figura 3). Na taxa de $5^{\circ} \mathrm{C} / \mathrm{min}$ a isoterma obtida é do tipo I, característica de uma adsorção em meios microporosos, onde ocorre a saturação em baixas concentrações, formando uma monocamada completa. Já nas taxas de 10 e $15^{\circ} \mathrm{C} / \mathrm{min}$, observa-se a formação de uma isoterma do tipo II, com a formação de uma monocamada no momento em que foi adsorvido cerca de $0,45 \mathrm{~kg}$ de ácido acético/ $\mathrm{kg}$ de char. Após este ponto pode-se dizer que houve a formação de multicamadas, aumentando gradativamente a quantidade de adsorbato no char. A formação de multicamadas é característica de materiais macroporosos (Schmal, 2011). Desta forma, em taxas mais baixas é obtido um char com diâmetro de poros menores do que em taxas mais altas. Essa característica permite indicar o char formado na taxa de $5{ }^{\circ} \mathrm{C} / \min$ para a aplicação onde a característica de microporos seja desejada. 


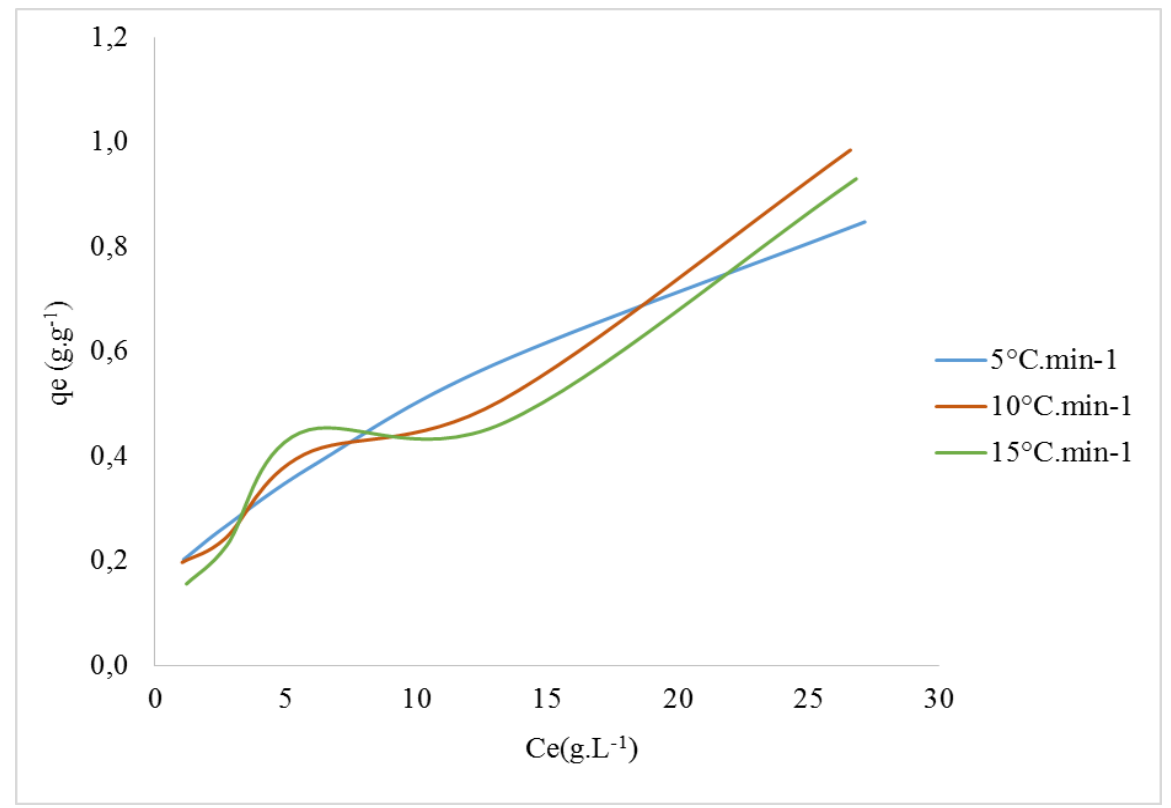

Figura 3 - Isotermas de adsorção.

Embora os resultados indicaram que o char obtido na taxa de $5{ }^{\circ} \mathrm{C} /$ min pode ser utilizado em aplicações onde a característica de microporos seja desejada, sugere-se a ativação para a obtenção de um material com uma porosidade maior.

\section{CONCLUSÕES}

A partir dos resultados apresentados pode ser evidenciado, através da análises de MEV, que o char produzido apresentou morfologia porosa e mudanças nas propriedades estruturais após o processo de pirólise. $\mathrm{O} \mathrm{MEV}$ também apontou uma maior degradação do material para a taxa de aquecimento de $15^{\circ} \mathrm{C} / \mathrm{min}$. Também foi possível determinar que na taxa de $5{ }^{\circ} \mathrm{C} / \mathrm{min}$ observase a formação de char com tamanho de poros menores e em quantidade mais elevada. Nesta mesma taxa, a isoterma de adsorção segue o modelo de monocamadas. Nas demais taxas, 10 e 15 ${ }^{\circ} \mathrm{C} / \mathrm{min}$, observou-se poros maiores e desuniformes, o que resultou em isotermas em multicamadas. Sendo assim, o carvão obtido na taxa de aquecimento de $5{ }^{\circ} \mathrm{C} /$ min pode ser aplicado em processos de separação por adsorção, porém uma ativação se faz necessária.

\section{REFERÊNCIAS}

ANNADURAI, G., LING, L. Y., LEE, J. Adsorption of reactive dye from an aqueous solution by chitosan: isotherm, kinetic and thermodynamic analysis. J. Hazard. Mater., [S.1],v. 152, p. 337-346, 2008. 
BRIDGWATER, A.; MEIER, D.; RADLEIN, D. Renewable fuels and chemicals by thermal processing of biomass. Chem. Eng. J., [S.1], v. 91, p. 87-102. 15 mar. 2003.

CAVALCANTE, C. L. Separação de misturas por adsorção: dos fundamentos ao processamento em escala comercial. 1998. 65 f. Tese submetida a concurso público para professor titular do Departamento de Engenharia Química da Universidade Federal do Ceará, Ceará, 1998.

CETIN, E.; GUPTA, R.; MOGHTADERI, B. Effect of pyrolysis pressure and heating rate on radiate pine char structure and apparent gasification reactivity. Fuel, [S.1], v. 84, n. 10, p.1328-1334, jul. 2005.

SCHMAL, M. Catálise heterogênea. Rio de Janeiro: Synergia, 2011.

SHARMA, R. K.; WOOTEN, J. B.; BALIGA, V. L.; HAJALIGOL, M. L. Characterization of chars from biomass-derived materials: pectin chars. Fuel, [S.1.], v. 80, p. 1825-1836, 2001.

SOYHAN, H. S. Sustainable energy production and consumption in Turkey: A review. Renewable And Sustainable Energy Rev., [S.1], v. 13, p. 1350-1360, ago. 2009.

STREZOV, V.; EVANS, T. J.; HAYMAN, C. Thermal conversion of elephant grass (Pennisetum Purpureum Schum) to bio-gas, bio-oil and charcoal. Bioresour. Technol., New York, v. 99, p. 8394-8399, 2008.

SUlAYMON, A. H., ABID, B. A., AL-NAJAR, J. A. Removal of lead copper chromium and cobalt ions onto granular activated carbon in batch and fixed-bed adsorbers. Chem. Eng. J., [S.1], v. 155, p. 647-653, 2009. 